\title{
Epidemiology of blindness and visual impairment in the kingdom of Tonga
}

\author{
H S Newland, A J Woodward, L A Taumoepeau, N S Karunaratne, I G M Duguid
}

\begin{abstract}
Data on the prevalence and causes of blindness and visual impairment in Polynesians are not readily available nor are they population based. This survey was designed to obtain an accurate estimate of blindness and its causes in Tonga. A sample of 4056 persons, aged 20 years and over, was selected by stratified cluster sampling. Participants received a screening, visual acuity examination, and, if visually impaired, were referred for detailed ophthalmic examination to determine the cause. The prevalence of bilateral blindness in the study population was $0.47 \%$ and all affected were aged over 50 years. It is estimated that the national prevalence of bilateral blindness, adjusted for the sample weight applied in the selection procedure, is $0.56 \%(95 \%$ confidence interval $0-1 \cdot 13)$. Monocular blindness was three times more frequent. Cataract was responsible for $\mathbf{6 8 . 4 \%}$ of bilateral and $30.3 \%$ of monocular blindness. Risk factors for life time experience of cataract included age and diabetes (self-reported). Neither smoking nor the presence of pterygium were independently associated with cataract. Increasing years of education were protective against cataract for women, but not men. Corneal opacity from infection or trauma, and diabetes were responsible for most of the remaining visual impairment. While these results do not represent a significant public health problem by world standards they do provide a basis for planning blindness prevention programmes in the region.

(Brf Ophthalmol 1994; 78: 344-348)
\end{abstract}

International Community

Eye Care, Flinders

Medical Centre, South

Australia 5042, Australia

H S Newland

Department of

Community Medicine,

University of Adelaide,

South Australia 5000,

Australia

A J Woodward

Ministry of Health,

Nuku'alofa, Tonga

L A Taumoepeau

ASPECT Foundation

Ltd (Australian South

Pacific Eye Consultant

Team), Ford Street,

Ringwood, Victoria 3134,

Australia

N S Karunaratne

I G M Duguid

Correspondence to:

H S Newland, Flinders

Medical Centre, Bedford

Park, South Australia 5042, Australia.

Accepted for publication

21 October 1993
There are few reliable statistics on the magnitude and causes of visual impairment in Polynesians. In 1981, it was estimated by the World Health Organisation that the prevalence of bilateral blindness in Tonga was $0.4 \%$ ( 385 persons in a population of approximately 96000$).{ }^{1}$ In the same year, the prevalence of bilateral blindness in Vanuatu, a Melanesian population, was estimated to be $0 \cdot 35 \%$. Later, an overall prevalence of bilateral blindness of $0.4 \%$ was found in Vanuatu after a population based survey was conducted in $1989 .{ }^{2}$ Cataract was responsible for $85 \%$ of this blindness. Population based surveys of visual impairment have been conducted in developing countries in Asia and Africa in recent years. In 1985, Brilliant et al estimated the prevalence of blindness in Nepal to be $0.84 \%$ with $67 \%$ of bilateral blindness being due to cataract. ${ }^{3}$ Several African surveys conducted according to WHO guidelines have suggested bilateral blindness rates of $0.3 \%$ in the Congo, $1.26 \%$ in Tanzania, ${ }^{5}$ and $1.5 \%$ in Saudi Arabia. ${ }^{6}$ In all surveys, cataract was responsible for more than half of all blindness. However, population based data are lacking for Tonga which poses significant problems in planning prevention of blindness programmes. In order to obtain an accurate estimate of blindness and its causes, this survey was initiated by ASPECT and conducted with the government of Tonga.

The kingdom of Tonga has a population of approximately 100000 , half of whom are aged less than 20 years. Tonga consists of 170 islands, 40 of them populated, spread across 360000 square kilometres of ocean. Two thirds of the population live on the main island, Tongatapu, which includes the capital of the kingdom, Nuku'alofa. One national ophthalmologist, based in Nuku'alofa, is responsible for tertiary eye care services and the education of nurses and trainee health officers. There are budgetary restrictions on travel to many, especially the more remote, islands.

Cataract is a particularly important cause of blindness and low vision, since it is a common condition and is usually treatable. Cataract has been reported in some studies to be more common in women than men, even with adjustment for age differences, and possible differences in access to surgery. Smoking has been found to be associated with cataract in several studies, both cohort and case-control investigations, ${ }^{7}$ although the possible mechanism is not known. In developed and developing countries cataract is disproportionately common among the poor and disadvantaged. This may be due to differences in treatment, or differences in incidence of disease (for example, through sun exposure, dietary differences [high intakes of dietary antioxidant are reported to be protective], or as a result of severe dehydrating diseases in early life) ${ }^{8} \mathrm{Hard}$ ing claims that pterygium and cataract are not related (if so, this would tend to count against the hypothesis that sunlight is a major aetiological factor for cataract, since pterygium is well known to be associated with cumulative ultraviolet $B$ exposure. ${ }^{8}$ This study provided an opportunity to test whether such an association existed in a population living at low latitudes.

\section{Sampling}

The study was restricted to persons aged 20 years and over, owing to the anticipated low prevalence of blindness and low vision in younger age groups. The study aimed to obtain information on approximately 3500 persons, based on estimates of the prevalence of blindness and the resources available for conduct of the study. Anticipating a response rate of approximately $70 \%$, a sample of 5000 (10\% of the national adult population) was selected. The study population was selected by stratified cluster sampling, based on the results of 
the 1986 national census. The national population was first broken down into the five statistical divisions that correspond to the principal island groups. The northern most group (the Niuas) was excluded from the study because of its inaccessibility and its small population $(2 \cdot 1 \%$ of the national total). Within each division, we excluded islands with populations of less than 100 , and those without permanent residents, most of which are tourist resorts.

In each of the four remaining divisions, villages were selected randomly until the accumulated number of adults aged 20 and over exceeded $10 \%$ of the total in the division. In the case of the two island groups with widely dispersed populations (Ha'apai and Vava'u), villages were grouped before sampling into those that could be reached by road from the airstrip ('central'), and those that could be reached only by boat ('remote'). To conserve limited resources, three quarters of the study population in each island group were selected from the central villages.

The principal town, Nuku'alofa, was sampled separately. A quota of $10 \%$ of the town's population aged 20 years and over was calculated, and the town divided into two areas of equal population (Kolofo'ou and Kolomotu'a plus Ma'ufuga). In each area a list of census blocks was drawn up, and one block selected randomly. An adjacent block was also selected at random, and then further adjacent blocks were included, moving clockwise around the index block, until the accumulated number of adults aged 20 years and over exceeded half the quota for the town.

The study sites, together with numbers of adults aged 20 and over and the number of households (as recorded in the 1986 census) are shown in Table 1. The sample consisted of 18 villages and 10 census blocks in Nuku'alofa, which altogether contained 5175 adults aged 20 and over.

\section{Blindness survey}

During July 1991, two teams examined a total of

\begin{tabular}{lcc}
$\begin{array}{l}\text { Table 1 Study sites, adults aged } 20 \text { and over, and } \\
\text { households (as recorded by the } 1986 \text { census) }\end{array}$ \\
\hline \multicolumn{2}{l}{ Population $20+$} & Households \\
\hline Study site & 1140 & 348 \\
\hline Nuku'alofa: & 502 & 140 \\
Kolofo'ou & 638 & 208 \\
Kolomotu'a and Ma'ufuge & 2035 & 698 \\
Tongatapu: & 301 & 108 \\
Longoteme & 109 & 41 \\
Nukuleka & 160 & 54 \\
Makaunga & 825 & 280 \\
Laphaha & 391 & 139 \\
Kolovai & 126 & 37 \\
Masilamea & 123 & 39 \\
Ha'avakatolo & 229 & 92 \\
Eua: & 118 & 44 \\
Futu & 111 & 48 \\
Mata'aho & 889 & 307 \\
Ha'apai: & 453 & 164 \\
Hihifo & 119 & 41 \\
Fotua & 87 & 30 \\
Pukotala & 230 & 72 \\
Ha'afeva Island & 882 & 328 \\
Vava'u: & 153 & 52 \\
Neiafu (census block 9) & 242 & 87 \\
Mataika & 221 & 82 \\
Taoa & 99 & 69 \\
Falevai & 167 & 173 \\
Hunga Island & 5175 & \\
Total & & \\
\hline & &
\end{tabular}

4056 persons in all sites. The study teams included nurses and trainee health officers from the Department of Health, kingdom of Tonga and two registrars in ophthalmology (NSK and IGMD). The teams participated in a 3 day training course before field work. Questionnaires and eye examination techniques were piloted in Nuku'alofa.

At each village or census block, all houses were visited and the number of occupants in each household was documented. Each occupant aged 20 years or more was questioned regarding age, education, smoking status, diabetes, and any history of ocular disease.

Visual acuity was then measured beside the house. The health worker placed a plastic coated E type or Snellen chart at 6 metres and the subject was asked to identify the direction of the $E$ or the letter. If visual acuity was $6 / 18$ or better, the examination ended. If the identification was not correct, optotypes for $6 / 60,3 / 60$ (at 3 metres), and 1/60 (at 1 metre) were shown until a successful result was obtained. If the examinee could not see the optotype at a distance of 1 metre (that is, counting fingers), the health worker recorded the subject's perception of light or assessed the ability to fix and follow a focused light source during the ophthalmic examination. Participants unable to see at least $6 / 18$ were offered a pinhole correction and any improvement was noted. All participants were tested using the best correction (that is, pinhole or glasses), and those with visual impairment were referred to the ophthalmologist for assessment of the cause.

A basic eye examination was then conducted by the health worker using a hand torch. Patients with any abnormality were referred to the ophthalmologist for assessment and treatment.

The ophthalmic examination included an assessment of the anterior segment and of the posterior pole through a pupil dilated with $10 \%$ phenylephrine and $1 \%$ tropicamide. The diagnosis of the cause of any visual impairment and aetiology of any ocular disorders were recorded.

All data were recorded on the WHO/PBL eye examination record. ' The data collection forms were checked, sorted, and forwarded to Adelaide for coding and entry. The d-Survey program was used for entering and checking the data. Statistical analysis was carried out using SYSTAT and SAS-PC (SAS institute, NC, USA).

\section{Statistical methods}

The study population represented a stratified cluster sample, with few clusters selected per stratum, some oversampling (among the 'central' villages in Ha'apai and Vava'u), and variable response rates.

Prevalence estimates were calculated using the method of Cochran, to adjust for the effects of the sampling method. ${ }^{10}$ Confidence intervals were derived from estimates of variance, also based on Cochran.

Stratified analyses were carried out using the SYSTAT and SAS-PC statistical packages and the appropriate standard statistical tests (CochranMantel-Haenszel $\chi^{2}$ test). The multivariable analysis was undertaken using the LOGISTIC pro- 
Table 2 Distribution of survey participants by district and sex (percentage of 1986 census population shown in brackets)

\begin{tabular}{lrrrr}
\hline District & Men & Women & Total & $(\%)$ \\
\hline Nuku'alofa & 379 & 492 & 871 & $(8 \cdot 5)$ \\
Tongatapu & 721 & 852 & 1573 & $(8 \cdot 4)$ \\
Eua & 90 & 92 & 182 & $(8 \cdot 9)$ \\
Vava'u & 314 & 394 & 708 & $(9 \cdot 9)$ \\
Ha'apai & 315 & 407 & 722 & $(16.8)$ \\
Total & 1819 & 2237 & 4056 & $(9 \cdot 5)$
\end{tabular}

(Sampling fraction for total population excludes Niuas)

Table 3 Age and sex distribution of persons surveyed in Tonga, 1991

\begin{tabular}{lrcc}
\hline Age group (years) & Male & Female & Total $(\%)$ \\
\hline $20-24$ & 339 & 358 & $697(17 \cdot 2)$ \\
$25-29$ & 226 & 267 & $493(12 \cdot 2)$ \\
$30-34$ & 175 & 245 & $420(10 \cdot 4)$ \\
$35-39$ & 159 & 221 & $380(9 \cdot 4)$ \\
$40-44$ & 131 & 202 & $333(8 \cdot 2)$ \\
$45-49$ & 137 & 186 & $323(8 \cdot 0)$ \\
$50-54$ & 151 & 193 & $344(8 \cdot 5)$ \\
$55-59$ & 131 & 156 & $287(7 \cdot 1)$ \\
$60-64$ & 122 & 129 & $251(6 \cdot 2)$ \\
$65-69$ & 88 & 90 & $178(4 \cdot 4)$ \\
$70-74$ & 64 & 84 & $148(3 \cdot 6)$ \\
$75-79$ & 54 & 48 & $102(2 \cdot 5)$ \\
$80-84$ & 20 & 26 & $46(1 \cdot 1)$ \\
$85+$ & 22 & 32 & $54(1 \cdot 3)$ \\
Total & 1819 & 2237 & $4056(100 \cdot 0)$ \\
\hline
\end{tabular}

cedure in SAS. All main effects were included initially, and then a stepwide procedure was used to study significant interactions.

\section{Results}

Table 2 shows the distribution of the study population by district and sex. The number of people included in the study is $9.5 \%$ of the 1986 census population of Tonga. The age distribution of study participants is shown in Table 3 , by the age categories reported in the 1986 Tongan census. The proportion of the census number in each age group that was included in the survey varied from $7 \cdot 8 \%$ (20-24 years) to $11 \cdot 6 \%(50+$ years). As the survey progressed the percentage of the 1986 census population examined in each district increased. The overall prevalence of binocular blindness in the 20 years and over population was $0.56 \%$ (95\% confidence interval $0-1 \cdot 13)$ and all those affected were aged more than 50 years. Blindness rates increased steeply among those aged 60 and over (Fig 1). Monocular blindness was more than three times more common than bilateral blindness.

The best estimate of the national prevalence of

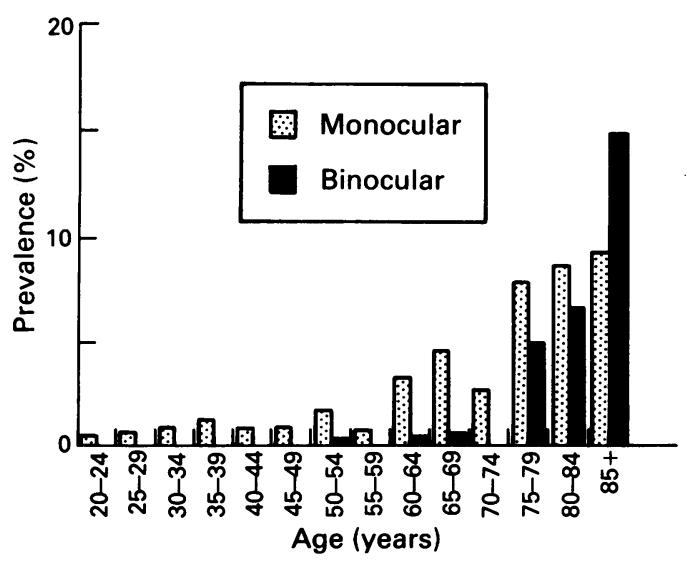

monocular blindness, calculated by the method of Cochran, was $16 \cdot 7 \%$ per 1000 (95\% CI $11 \cdot 0$ 22.5). The adjusted prevalence estimate for binocular blindness was $5 \cdot 6 \%$ per $1000(95 \% \mathrm{CI}$ 0-11·3).

Table 4 shows the causes of monocular and bilateral blindness in the surveyed population. Cataract was responsible for $68 \cdot 4 \%$ of bilateral

Table 4 Causes of monocular and binocular blindness *

\begin{tabular}{|c|c|c|c|c|}
\hline \multirow[b]{2}{*}{ Cause } & \multicolumn{2}{|c|}{ Monocular blindness } & \multicolumn{2}{|c|}{ Bilateral blindness } \\
\hline & $\overline{N o}$ & $(\%)$ & No & $(\%)$ \\
\hline Cataract & 20 & $(30 \cdot 3)$ & 13 & $(68 \cdot 4)$ \\
\hline Aphakia & 3 & $(4 \cdot 6)$ & 0 & - \\
\hline Pseudophakia & 1 & $(1.5)$ & 0 & - \\
\hline Phthisical eye & 19 & $(28 \cdot 8)$ & 2 & $(10 \cdot 5)$ \\
\hline Corneal opacity & 8 & $(12 \cdot 1)$ & 3 & $(15 \cdot 8)$ \\
\hline Glaucoma & 2 & $(3 \cdot 0)$ & 0 & - \\
\hline Optic atrophy & 2 & $(3 \cdot 0)$ & 0 & - \\
\hline Diabetes & 3 & $(4 \cdot 6)$ & 1 & $(5 \cdot 3)$ \\
\hline Amblyopia & 1 & $(1 \cdot 5)$ & 0 & - \\
\hline Other & 7 & $(10 \cdot 6)$ & 0 & - \\
\hline Total & 66 & $(100 \cdot 0)$ & 19 & $(100 \cdot 0)$ \\
\hline
\end{tabular}

^ Bilateral blindness defined according to WHO criteria of visual acuity $<3 / 60$ in the better eye. Monocular blindness defined as visual acuity in one eye of $<3 / 60$.

Table 5 Causes of low vision in the survey (bilateral) ${ }^{\star}$

\begin{tabular}{lrr}
\hline Cause & No & $(\%)$ \\
\hline Cataract & 29 & $(83 \cdot 0)$ \\
Refractive error & 1 & $(3 \cdot 0)$ \\
Pseudophakia & 1 & $(3 \cdot 0)$ \\
Corneal opacity & 1 & $(3 \cdot 0)$ \\
Diabetes & 1 & $(3 \cdot 0)$ \\
Macular degeneration & 1 & $(3 \cdot 0)$ \\
Amblyopia & 1 & $(3 \cdot 0)$ \\
Total & 35 & \\
\hline
\end{tabular}

* Bilateral visual impairment defined as acuity less than $6 / 18$ but better than or equal to $3 / 60$ in the better eye.

Table 6 Need for cataract surgery by district

\begin{tabular}{lccl}
\hline District & $\begin{array}{l}\text { No of } \\
\text { operable } \\
\text { cataracts }\end{array}$ & $(\%)$ & $\begin{array}{l}\text { Prevalence } \\
\text { (per 1000 } \\
\text { persons) }\end{array}$ \\
\hline Nuku'alofa & 16 & $(15 \cdot 1)$ & $18 \cdot 4$ \\
Tongatapu & 48 & $(45 \cdot 3)$ & $30 \cdot 5$ \\
Eua & 4 & $(3 \cdot 8)$ & $22 \cdot 0$ \\
Ha'apai & 12 & $(11 \cdot 3)$ & $16 \cdot 6$ \\
Vava'u & 26 & $(24 \cdot 5)$ & $36 \cdot 7$ \\
Total & 106 & $(100 \cdot 0)$ & $26 \cdot 1$ \\
\hline
\end{tabular}

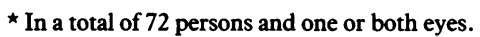

Table 7 Factors associated with lifetime experience of cataract (includes persons with cataract present, or a history of cataract surgery)

\begin{tabular}{|c|c|c|c|c|}
\hline & $\begin{array}{l}\text { Cataract } \\
(\%)\end{array}$ & $\begin{array}{l}\text { No } \\
\text { cataract }\end{array}$ & Total & $p^{\star}$ Value \\
\hline $\begin{array}{l}\text { Age: } \\
20-24 \text { years } \\
25-34 \text { years } \\
35-49 \text { years } \\
50+\text { years }\end{array}$ & $\begin{array}{r}2(0.29) \\
2(0.22) \\
9(0 \cdot 87) \\
112(7 \cdot 94)\end{array}$ & $\begin{array}{r}695 \\
911 \\
1027 \\
1298\end{array}$ & $\begin{array}{r}697 \\
913 \\
1036 \\
1310\end{array}$ & $<0.0001$ \\
\hline $\begin{array}{l}\text { Sex: } \\
\text { male } \\
\text { female }\end{array}$ & $\begin{array}{l}50(2 \cdot 75) \\
75(3 \cdot 35)\end{array}$ & $\begin{array}{l}1769 \\
2162\end{array}$ & $\begin{array}{l}1819 \\
2237\end{array}$ & $0 \cdot 268$ \\
\hline $\begin{array}{l}\text { Diabetes: } \\
\text { present } \\
\text { absent }\end{array}$ & $\begin{array}{r}19(16 \cdot 2) \\
106(2 \cdot 71)\end{array}$ & $\begin{array}{r}98 \\
3827\end{array}$ & $\begin{array}{r}119 \\
3933\end{array}$ & $<0.0001$ \\
\hline $\begin{array}{l}\text { Pterygium: } \\
\text { present } \\
\text { absent }\end{array}$ & $\begin{array}{l}40(3 \cdot 81) \\
85(2 \cdot 83)\end{array}$ & $\begin{array}{l}1010 \\
2921\end{array}$ & $\begin{array}{l}1050 \\
3006\end{array}$ & $0 \cdot 113$ \\
\hline $\begin{array}{l}\text { Ever smoked: } \\
\text { yes } \\
\text { no }\end{array}$ & $\begin{array}{l}65(3 \cdot 90) \\
60(2 \cdot 51)\end{array}$ & $\begin{array}{l}1600 \\
2328\end{array}$ & $\begin{array}{l}1665 \\
2388\end{array}$ & 0.012 \\
\hline $\begin{array}{l}\text { Years of education: } \\
\text { (mean) }\end{array}$ & $7 \cdot 3$ years & $9 \cdot 2$ years & & 0.0001 \\
\hline
\end{tabular}


Table 8 Factors associated with lifetime experience of cataract - results of logistic regression

\begin{tabular}{|c|c|c|c|c|}
\hline Variable & $\begin{array}{l}\text { Parameter } \\
\text { estimate }\end{array}$ & Standard error & Odds ratio & $\begin{array}{l}95 \% \text { Confidence } \\
\text { interval }\end{array}$ \\
\hline $\begin{array}{l}\text { Age (years) } \\
\text { Education (years) }\end{array}$ & $0 \cdot 10$ & 0.008 & $1 \cdot 11$ & $1 \cdot 09-1 \cdot 12$ \\
\hline male & $\begin{array}{l}-0.01 \\
-0.21\end{array}$ & $\begin{array}{l}0.062 \\
0.074\end{array}$ & $\begin{array}{l}0.99 \\
0.81\end{array}$ & $\begin{array}{l}0 \cdot 87-1 \cdot 12 \\
0 \cdot 70-0.94\end{array}$ \\
\hline $\begin{array}{l}\text { Ever smoked } \\
\quad(\text { yes } v \text { no })\end{array}$ & $0 \cdot 21$ & $0 \cdot 226$ & 1.24 & $0.79-1.92$ \\
\hline $\begin{array}{l}\text { Diabetes } \\
\quad \text { (yes } v \text { no) }\end{array}$ & 1.46 & 0.313 & $4 \cdot 28$ & $2 \cdot 32-7 \cdot 91$ \\
\hline $\begin{array}{l}\text { Pterygium } \\
\text { (yes } v \text { no) } \\
\text { District }^{\star}\end{array}$ & -0.48 & 0.322 & 0.62 & $0.40-0.95$ \\
\hline $\begin{array}{l}2 v 1 \\
3 v 1 \text { male } \\
\quad \text { female } \\
4 v 1 \\
5 v 1 \\
6 v 1\end{array}$ & $\begin{array}{l}0.91 \\
0.53 \\
1.72 \\
1.62 \\
0.93 \\
1.15\end{array}$ & $\begin{array}{l}0.588 \\
0.573 \\
0.539 \\
0.637 \\
0.535 \\
0.540\end{array}$ & $\begin{array}{l}2 \cdot 49 \\
1 \cdot 70 \\
5 \cdot 61 \\
5 \cdot 06 \\
2 \cdot 54 \\
3 \cdot 17\end{array}$ & $\begin{array}{l}0 \cdot 79-7 \cdot 89 \\
0 \cdot 55-5 \cdot 21 \\
1 \cdot 95-16 \cdot 1 \\
1 \cdot 45-17 \cdot 6 \\
0 \cdot 89-7 \cdot 25 \\
1 \cdot 10-9 \cdot 13\end{array}$ \\
\hline
\end{tabular}

^ Districts $1=$ Kolofo'ou; $2=$ Kolomotu'a; 3=Tongatapu; 4=Eua; 5=Ha'apai; 6=Vava'u.

and $30.3 \%$ of monocular blindness. Corneal opacity was the cause of $15 \cdot 8 \%$ (three cases) of bilateral blindness, due to trachoma, infection, and recurrent pterygia obscuring the visual axis. Bilateral phthisical bulbi was found in two cases, one due to complications following StevensJohnson syndrome while in the other, trauma and endophthalmitis were responsible. One person was bilaterally blind from diabetic retinopathy. Nineteen persons $(28 \cdot 8 \%)$ were monocularly blind with phthisical eyes, most due to trauma. Pseudophakia and aphakia accounted for four blind eyes $(6 \cdot 1 \%)$ while corneal opacity was found in eight persons $(12 \cdot 1 \%)$. Diabetic retinopathy caused monocular blindness in three persons (4.6\%). Glaucoma, optic atrophy, amblyopia, and others were implicated in the remainder of cases. Many of the blind were old and infirm and unable to recall the cause of their blindness.

Table 5 shows the causes of low vision in the survey $(1 \cdot 8 \%$ of persons had acuity less than $6 / 18$ but better than or equal to $3 / 60$ in the better eye), $29(83 \%)$ were caused by cataract while other causes included diabetic retinopathy and pseudophakia.

Table 6 shows the number of operable cataracts, as determined by the attending ophthalmologists, by district. A total of $64(60 \cdot 4 \%)$ were in Nuku'alofa or on the main island Tongatapu where eye services are most easily available.

Factors associated with lifetime cataract are shown in Tables 7 and 8 (logistic regression).

\section{Discussion}

The results of this survey provide the first objective measure of the prevalence of blindness and visual impairment in a Polynesian population. The prevalence of bilateral blindness in those aged 20 years and over in Tonga is estimated to be $0.56 \%$. Persons aged under 20 years make up approximately $54 \%$ of the Tongan population, and probably include very few persons bilaterally blind. Therefore, the prevalence of blindness in Tonga, all ages included, is likely to be close to $0 \cdot 26 \%$. This is the relevant figure for health service planners, who must estimate the likely burden of blindness nationally. International comparisons of blindness prevalence must allow for the different age structures of national populations. The Tongan blindness estimate (bilateral, aged 20 and over) standardised using the age structure of the standard world population, ${ }^{11}$ was $0.33 \%$.

The number of participants in the study represented $78 \%$ of the population in the study areas, as recorded in the 1986 census. It is likely that older residents are overrepresented in the study group, compared with the national population. (The 50 and over age group made up $27 \cdot 7 \%$ of all Tongans over 20 in the 1986 census. In this study, the 50 and over category comprised $34 \cdot 7 \%$ of the total.) Males were underrepresented in the study population (sex ratio 0.813 , ratio of men:women in 1986 census 0.941 ). The age profile of participants, and the clear relation of blindness to increasing age suggest that the study may have overestimated the true national blindness prevalence rates. The most common reasons for non-response, especially among males, were absence overseas or elsewhere in Tonga, on holiday or temporary employment, and absence locally, fishing or gardening. Only four persons who were contacted refused to take part in the survey. There were no known instances of nonresponse due to absence for medical treatment of serious eye disease. In these circumstances blindness may be less common among persons who were eligible to take part in the study but did not participate, compared with those who did take part.

In the only other population based survey in the region, in Vanuatu, the prevalence of bilateral blindness (all ages) was found to be $0.4 \%$. $^{2}$

The lower prevalence in Tonga would certainly be due in part to the permanent presence of an ophthalmologist in Nuku'alofa, whereas specialised care in Vanuatu is only short term. Logistically, Vanuatu is more isolated than Tonga, with more islands, many of which are accessible only by sea. This may result in much of the population not being able to make use of limited eye health care.

These two surveys provide the baseline data for planning blindness prevention programmes for the South Pacific. The prevalence of blindness rate of $0.26 \%$ is half the $0.5 \%$ rate that is the goal of the WHO programme for the prevention of blindness to eliminate the burden of avoidable blindness. ${ }^{12}$ However, it is reasonable to assume that cataract blindness is readily reversible in Tonga and therefore more than $60 \%$ of bilateral and $30 \%$ of monocular blindness could be cured.

This survey did not attempt to identify all cases of cataract in the study population. Health workers carried out a general eye examination with hand torch, and noted lens opacities that were visible. A full eye examination was performed by one of the ophthalmologists only in persons whose corrected vision was less than $6 / 18$ in either eye. Therefore, the cataracts identified in this study are chiefly those associated with (and generally, responsible for) visual impairment.

Among 4056 persons surveyed, 52 were reported to have lens opacities in one eye, and 53 had opacities in both eyes (prevalence of persons with cataract of $2 \cdot 6 \%$ ). The examining doctor judged that cataract surgery was indicated in 72 out of 105 persons reported to have cataract (106 
eyes). On the basis of this result, we estimate that there are in Tonga approximately 760 persons with untreated cataract associated with visual impairment or blindness, and suitable for surgery, among persons aged 20 and over. Assuming that the average duration of this condition (the time from diagnosis to death) is about 5 years ${ }^{13}$ we estimate that there are in total approximately 150 new cases of disabling cataract arising each year, in addition to the $100-150$ cases that are currently recognised and treated. Both the prevalence and absolute number of the operable cataracts are likely to be highest in Tongatapu and Vava'u, the two most densely populated islands. When considering the services available to respond to this morbidity, it is interesting that almost two thirds of the operable cataracts identified in this study were on the main island, where there is a permanent ophthalmologist. There is a need for improved case finding in Tongatapu and Vava'u. It appears that, in the past, the smaller populations on outlying islands may have received a better service from visiting eye teams than the larger populations in the major centres.

In the survey populations the number of persons judged to require cataract surgery (72) was three times greater than the number who had received surgery for the condition (24). This is strong evidence of unmet need for eye services. Among all persons who had once suffered from cataract, the probability of receiving surgery was highest in Tongatapu (0.31) and lowest in Vava'u (0.05).

Studies elsewhere have shown that social factors may be important in determining who receives treatment, regardless of distance from services. For example, in Nepal it was found men were more likely to receive cataract surgery than women, and wealth was also associated with surgery.${ }^{14}$ In Tonga, the probability of receiving surgery was the same for men and women. The study included no direct measure of disposable income or wealth. Those requiring surgery had fewer years of education than the recipients of surgery, but the difference was small and not statistically significant. Neither was age a relevant factor (mean ages 71.5 years for persons receiving surgery, $73 \cdot 1$ years for those requiring surgery, $p=0 \cdot 4$ ).

Risk factors for lifetime cataract were examined. Cases included persons found to have cataract at survey and persons who had received cataract surgery in the past. In bivariate analyses age and diabetes were strongly associated with experience of cataract; weaker associations were found for sex, pterygium, and years of education. The prevalence of cataract was $50 \%$ higher among those who had ever smoked than among lifetime non-smokers (Table 7). The association with a history of smoking was due principally to a high proportion (11\%) of ex-smokers experiencing cataract.

In the multivariate analysis, the association with age and diabetes status remained statistically significant, but sex and smoking status no longer acted as independent risk factors that were statistically significant (Table 8). The association with pterygium was reversed (that is, the presence of pterygium was associated with absence of cataract, when adjustment was made for other risk factors). Therefore, these data are consistent with the view that cataract and pterygium do not have common aetiologies.

Increasing years of education was associated with reduced frequency of cataract in women, but not in men. Compared with the capital city (as represented by district 1), lifetime cataract was observed more frequently in Tongatapu (females only), Eua and Vava'u. It is not clear what environmental conditions or lifestyle factors may explain these differences.

It is of some concern that diabetes was most strongly associated with cataract (adjusted odds ratio $4 \cdot 28$ ) as this condition is likely to become increasingly important in Tonga as a cause of cataract and other serious eye conditions. (Already diabetic retinopathy is responsible for $5 \%$ of blindness in one or both eyes, and 3\% of low vision.) There is a need for further research on the natural history of diabetic eye disease in this population.

The low prevalence of blinding glaucoma is in keeping with the findings in Vanuatu and with those of a survey of Australian aborigines. ${ }^{15}$ The present survey did not attempt to screen for early stages of glaucoma.

We thank the following for their support and assistance: Australian International Development Assistance Bureau; ASPECT Foundation; Department of Health nurses - Kelela Taufa, Florence Tupou, Mele Pongi, Lesieli Paliulu; trainee health officers - Losaline Faleta, William Falevai, Primrose Finau, Tupou Katiloha, Paeahe-Lotu Langoia, Liliani 'Otutaka, Sione Tu'ipulotu, Ofa Tu'itavulu; Ministry of Health - Dr Sope Foliaki, Dr Maika Kinahoi, Ms Krystyn Willson, and Dr Philip Ryan Tith statistical analysis.

This study was conducted in full accordance with provisions of the Declaration of Helsinki; and the free and informed consent of the subjects was obtained.

1 Maitchouk IF. Data on blindness prevalence and causes throughout the world. Unpublished WHO document PBL/82.1, 1981

2 Newland HS, Harris MF, Iwasaki W, Momomura K, Walland M, McKnight D, et al. Epidemiology of blindness and visual impairment in Vanuatu. Bull WHO 1992; 70: 369-72.

3 Brilliant LB, Pokhrel RP, Grasset NC, Lepkowski JM, Kolstad A, Hawks W, et al. Epidemiology of blindness in Nepal. Bull WHO 1985; 63: 375-86.

4 Negrel AD, Massemba-Yako B, Botaka E, Minassian DC, Coddy-Zitsamate R. Prévalence et causes de la cécité Congo. Coddy-Zitsamate R. Prévale

5 Rapoza PA, West SK, Katala SJ, Taylor HR. Prevalence and causes of vision loss in central Tanzania. Int Ophthalmol 1991; 15: 123-9.

6 Tabbara KF, Ross-Degnan D. Blindness in Saudi Arabia. fAMA 1986; 255: 3378-84.

7 Van Heyningen R, Harding JJ. A case-control study of cataract in Oxfordshire: some risk factors. Br F Ophthalmol 1988; 72: 804.

8 Harding JJ. Epidemiology and risk factors for cataract. Eye 1987; 1: 537.

9 Coding instructions for the WHO/PBL eye examination record (version III). Unpublished WHO document PBL/88.1.

10 Cochran WG. Sampling techniques. 3rd ed. New York: John Wiley, 1977.

11 Waterhouse J, Munt C, Shanmugaratnam K, Powell J, eds. Cancer incidence in five continents. Vol IV. Lyon: International Agency for Research on Cancer, 1982.

12 Guidelines for programmes for the prevention of blindness. Geneva: World Health Organisation, 1979.

13 Steinkuller PG. Cataract: the leading cause of blindness and vision loss in Africa. Soc Sci Med 1983; 17: 1693-702.

14 Brilliant GE, Brilliant LB. Using social epidemiology to understand who stays blind and who gets operated for cataract in a rural setting. Soc Sci Med 1985; 21: 553-8.

15 Taylor HR, Hollows FC, Moran D. Pseudoexfoliation of the lens in Australian aborigines. Br 7 Ophthalmol 1977; 61: 473. 